Case report

\title{
Tumor - Induced Osteomalacia Associated with a Maxillary Tumor in Children: A Case Report and Review of the Literature
}

\section{Short title: Maxillary Tumor-induced Osteomalacia in Children}

Ha Nguyen Thi ${ }^{1}$, Cuong Pham Manh ${ }^{2}$, Linh To Tuan ${ }^{3}$, Lan Anh Le Thi ${ }^{4}$, Nam Nguyen Thanh ${ }^{5}$, Soamarat Vilaiyuk ${ }^{6}$

${ }^{I}$ Pediatric Department, Bach Mai Hospital. Ha Noi Medical University, Viet Nam

${ }^{2}$ Diagnostic Imaging Central, Bach Mai Hospital, Viet Nam

${ }^{3}$ Maxillofacial, Plastic and Aesthetic Surgery Department, Viet Duc Hospital, Viet Nam

${ }^{4}$ Pediatric Department, Bach Mai Hospital. Ha Noi Medical University, Viet Nam

${ }^{5}$ Pediatric Department, Bach Mai Hospital, Viet Nam

${ }^{6}$ Rheumatology Division, Pediatric Department. Faculty of Medicine Ramathibodi Hospital. Mahidol University, Thailand

What is already known on this topic?

Tumor-induced osteomalacia (TIO) is a rare syndrome characterized by severe hypophosphatemia and osteomalacia. Very few cases have been reported in children.

What this study adds?

We describe an adolescent diagnosed with TIO and we locate his tumor in right maxilla where is quite rare site. We review 5 pediatric TIO patients with tumors in oral and maxillary region. This suggests the importance of head and neck examination and suitable imaging for patients in whom TIO is suspected.

\section{ABSTRACT}

Tumor-induced osteomalacia (TIO) is a rare paraneoplastic disorder of hypophosphatemia associated with a tumor-producing fibroblast growth factor 23 (FGF23). The maxillofacial tumor is rarely involved in TIO, especially maxillary TIO in children. We presented a 14-year-old boy with osteomalacia and high serum levels of FGF23, a hormone associated with decreased phosphate resorption due to a maxillary tumor. The patient was treated with oral phosphorus and calcitriol, and received surgical removal of tumor. After 21 months follow-up, he was pain free and had returned to full activity. We reviewed 5 reports of pediatric patients with $T I O$ in oral and maxillofacial region. Tumors localized in mandible (2/5), maxilla (2/5), both mandible and maxilla (1/5). Mean time from onset of signs to diagnosis was 21,9 months.

Keywords: tumor-induced osteomalacia, fibroblast growth factor-23, maxilla, children

Ha Nguyen Thi, Pediatric Department, Bach Mai Hospital, Ha Noi Medical University, Viet Nam nguyenthiha_nhi@hmu.edu.vn

nguyenthiha_nh

20.08.2021

12.01 .2022

Published: 08.02.2022

\section{INTRODUCTION}

Tumor-induced osteomalacia is a rare paraneoplastic syndrome, first described in 1947 by McCance (1) but in 1959 Prader first highlighted the relation between the neoplasm and the disease in an 11-year-old girl who presented rickets in association with tumor of a rib (2). TIO is characterized by progessive bone pain, proximal muscle weakness, gait disturbance and multiple fractures, 
which are a consequence of severe hypophosphatemia. The key pathogenetic mechanism of TIO involves tumor-driven secretion of phosphatonins, most frequently fibroblast growth factor 23 (FGF23). FGF23 binds to the fibroblast growth factor receptor 1 - Klotho complex in the renal proximal tubule to stimulate the excretion of phosphorus in the kidney. High FGF23 levels reduce the expression of type Iia sodium phosphate contranspoters leading to renal phosphorus wasting (3). FGF23 is also a regulatory hormone for 1,25 dihydroxyvitamin D (1,25(OH)2D) and leads to a decreased concentration of the vitamin in blood. The majority of tumors associated with TIO are located in the extremites (skin, muscles, bones) or around the head, but the may occur in almost any part of the body. Few of pediatric patients have been reported - a 2015 review of TIO in pediatrics, the authors reported 26 children in the literature (4). Pharmacotheraphy is initiated with oral phosphorus and calcitriol supplementation, but surgical removal of the tumor is the definitive treatment of TIO (5).

We present a case of a 14-year-old boy who developed hypophosphatemia and urinary phosphate wasting, muscle weakness, bone pain and he had used wheelchair for 18 months. This is the first adolescent with TIO in Viet Nam.

We reported a previously healthy 14-year-old adolescent presented with 18 months of progressive, bilateral knee pain and ankle pain, as well as muscle weakness. He was able to walk slowly with crutches and was nearly wheelchair-bound. He had no fever and no weight loss. Because he has been misdiagnosed with juvenile idiopathic arthritis at the province hospital, he was prescribed non-steroid anti-inflammatory drugs, methotrexate and physical therapy. However, his condition did not improve over the subsequent six months and he was referred to our hospital in October 2019. At the time of presentation, his weight was at $50^{\text {th }}$ percentile for age, his height was at the $7^{\text {th }}$ percentile and he had no overt skeletal deformities. He had proximal weakness in bilateral upper and lower extremities. Although he was unable to walk due to pain, his joints were not swelling. The maxilla was neither pain nor enlarged. His family did not have history of hormonal, skeletal or metabolic problems.

\section{INVESTIGATIONS}

Laboratory test showed low serum ionized calcium (1.08 mmol/L, [reference range, $1.17-1.29 \mathrm{mmol} / \mathrm{L}])$, hypophosphatemia (0.32 $\mathrm{mmol} / \mathrm{L}$, [reference range, 0.87-1.45 mmol/L]), elevated alkaline phosphatase (1138 U/L, [reference range, 40-129 U/L]), low 1,25 (OH)2D (11/4 pg/ml, [reference range $16-65$ pg/ml]), normal 25-hydroxy vitamin D (19.6 ng/mL, [reference range, $>20 \mathrm{ng} / \mathrm{mL}$ ]), normal parathyroid hormone $(59.85 \mathrm{ng} / \mathrm{L}$, [reference range, $11-79 \mathrm{ng} / \mathrm{L}])$. The percent tubular reabsortion of phosphate was $85 \%$ (reference range, $>90 \%$ ); the maximal tubula renal phosphate reabsorption normalized for glomerular filtration rate (TmP/GFR) was $0.42 \mathrm{mmol} / \mathrm{L}$ (reference range, $1.15-2.44 \mathrm{mmol} / \mathrm{L}$ ). Serum FGF23 level was elevated at $159.3 \mathrm{pg} / \mathrm{mL}$ (reference range 23.2-95.4 pg/mL at Cerbra Laboratories, Paris, France).

Radiographs of skull and bones in upper and lower legs bilateral demonstrate generalized demineralization with decrease bone density, cortical thinning and blurring trabecular; fatigue fracture also seen in the cortex of right radius diaphysis accompany with widening of bilateral proximal humerus physis (Figure 1). A dual-energy X-ray absorptiometry (DXA) revealed an alarming loss of bone mineral density (BMD) at L1-L4 (0.498 g/ $\mathrm{cm}^{2}$, Z-score, -4.0$)$, the femoral neck $\left(0.448 \mathrm{~g} / \mathrm{cm}^{2}\right.$; Z-score,-3.6). Positron-emission tomography with ${ }^{18}$ Fluorodeoxyglucose $\left({ }^{18} \mathrm{FDG}-\mathrm{PET}\right)$ demonstrated a metabolically active lesion with increased standardized uptake values at in the right maxilla (Figure 2). Once the lesion was identified by the ${ }^{18}$ FDG-PET, magnetic resonance imaging (MRI) and computerized tomography (CT) scanner show a tumor measuring $23 \times 14 \mathrm{~mm}$ at the right maxilla (Figure 2).

\section{DIFFERENTIAL DIAGNOSIS}

The differential diagnosis of hypophosphatemia due to urinary phosphate wasting can be divided in to genetic and acquired causes. Inherited conditions include X-linked hyphophosphatemia $(\mathrm{XLH})$, autosomal dominant hypophosphatemia rickets, autosomal recessive hypophosphatemic rickets, and hereditary hypophosphatemic rickets with hypercalciuria (6). These diseases are often associated with short stature in early childhood, fractures, deformities in the legs and tooth findings. But the patient had the rapid onset of symptoms and the negative family history that rules out these causes.

Acquired causes include TIO, renal tubular damage from heavy metal exposure or drugs such as aminoglycoside antibiotics, vitamin D deficiency, and primary or secondary hyperparathyroidism. But the patient had normal serum PTH level and he did not use such drugs.

\section{TREATMENT}

The patient was medically mannaged with oral phosphorus ( 60 to $80 \mathrm{mg} / \mathrm{kg} / \mathrm{day})$ and calcitriol $(40 \mathrm{ng} / \mathrm{kg} / \mathrm{day})$, which improved but did not normalize his serum phosphorus. He had undergone surgical resection by 3 months after diagnosis. Histopathology examination indicated that the tumor was ossifying fibroma (OF) (Figure 3 ). One month after removal of the tumor, the patient's serum phosphorus level was $1.57 \mathrm{mmol} / \mathrm{L}$. Three months later, his serum FGF-23 level was normal (34.3 pg/mL), he was asymptomatic. One year later, DXA showed that his bone mineral density of the lumbar spine was recovered with normal Z-score (1.58). Twenty-one months since diagnosis, he was pain free and returned to full activity. He came back to school and has no evidence of tumor recurrence.

Through this report, we aim to highlight our experience with maxillary TIO in children and provide a review of published literature. Tumors associated with TIO may occur in lower extremity $(>40 \%)$ or craniofacial locations $(>20 \%)(7)$. On the whole, the maxillofacial region is rarely involved in TIO, especially maxillary TIO has made up $9 \%$ in location of neck and head $(8)$. 
We searched for all publications in English in Pubmed till August 2021 with key words "Tumor-induced osteomalacia", "Oncogenic Osteomalacia" and "Child". Only publications reporting pediatric TIO in the oral and maxillofacial area were included. We reviewed 5 cases of whom two were boys and three were girls, age from 3-18 year (Table 1). Associated tumors were found in mandible in 2 cases, maxilla in 2 cases and both mandible and maxilla in 1 case. The diagnosis of these TIO cases took loads of time, averaging 21.9 months (range 1.5 - 72 months). With our case, it took us about 18 months from onset to identification of the associated tumor but it is still shorter than the average time, especially patient 2 and patient 4 diagnosed after 24 months and 72 months respectively. The delay of diagnosis is due to several reasons. Firstly, the bone pain is just dismissed initially since this symptom may not yet be associated with radiographic abnormalities or obvious deformities. Secondly, serum phosphate is not routinely laboratory test. Lastly, the tumor's characteristic was quite small, hidden and clinically silent. Looking at the table 1 , the clinicians located tumor related TIO based on physical examination for the patient 3 , patient 4 and patient 5 who presented a tumor easily seen in the oral cavity while we had to perform ${ }^{18} \mathrm{FDG}$ PET/CT to find tumor. This considerable difference may be explained that in our case, the tumor was not only asyniptomatic but also invisible at its location. Besides, some articles reporting adult TIO showed that tumors without local symptoms were seen at over half of the number of patients with oral region lesions (55.9\%). On admission, we did not observe the patient 's maxillary alveolus because he had not any symptoms at this location. After the tumor was found by functional imaging tests $\left({ }^{18} \mathrm{FDG}-\mathrm{PET} / \mathrm{CT}\right)$, oral examinations were performed and none of which revealed any considerable findings. Therefore, the role of PET-CT is emerging, and it can be quite powerful as seen in this case. The current case had uncommon microscopic findings of the tumor, while the majority of the tumors that cause TIO are phosphaturic mesenchymal tumors (4). OF is a slow-growing benign lesion of bone most commonly associated with the jaws (9). According to the literature search, no publications describing OF tumor cause osteomalacia in children were found before. Diagnosis for TIO in our patient based on hypophosphatemia, hyperphosphaturia, high serum FGF23 level, and an inappropriately low 1,25-dihydroxy vitamin D. The improvement of serum phosphate level, serum FGF23 level, and clinical symptoms after tumor removal for the OF strongly implicated this tumor as the etiology for TIO. In our case, histophathology examination showed lesion related peripheral fibroma. Mesenchymal tumor can be divided in to osteomas, chondromas, mixed connective tissue tumors and fibroma, that all may produce a phosphatonin now called FGF23 (10). However, our limitation is not able to take immunohistochemical confirmation of FGF-23 production in resected tumor tissue.

Our patient was first treated by medical treatment for around 3 months before surgery. Because it took us much time to measure serum FG23 level for dianosis. Moreover, this is the first TIO case so we had to hold some consultations with many surgeons from another hospitals. After tumor removal our patient 's clinical symptoms remarkably improved and there was no sign of tumor recurrence. According to literature, the primary treatment of TIO is surgical resection the tumor but data on alternative therapies for TIO are limited, especially for children. Besides, it is necessary for clinicals to assess carefully muscular strength, serum phosphate levels and alkaline phosphatase concentrations because these problems may be difficulty in postsurgical management such as prolonged mechanical ventilator and delayed recovery (11). Additionally, intralesional corticosteroid injection after surgical removal has been reported in two pediatric patients 3 and patient 5 with central giant cell tumor (Table1). One of them was a 3-year-old boy with tumors in mandible and maxilla. The surgical removal was performed but CT imaging showed growth of tumor 4 months later so the patient was treated by injection of triamcinolone in maxillary and mandibular sites. As a result serum FGF-23 and phosphorus levels returned to normal 2 months later (12). Another patient was a 3-year-old boy who had a total tumor removal. Also, local instillation of triamcinolone resulted in disappearance of tumor 2 months after (13).

\section{CONCLUSION}

In conclusion, we reported a case with a rare cause of osteomalacia in childhood. Diagnosis is often delayed due to the slow progression of tumor thus physicians should perform careful investigation, extensive imaging, laboratory test, particularly serum phosphate and F GF-23 plasma levels and histopathological examination of the resected tumor. This case emphasizes that head and neck imaging play an important role for evaluation of patients with suspected TIO.

Informed Consent: A written informed consent was obtained from the patient sather.

\section{Authorship Contributions}

Surgical and Medical Practices: Ha Nguyen Thi, Cuong Pham Manh, Linh To Tuan, Concept: Ha Nguyen Thi, Cuong Pham Manh, Linh To Tuan, Lan Anh Le Thi, Nam Nguyen Thanh, Soamarat Vilaiyuk, Design: Ha Nguyen Thi, Cuong Pham Manh, Linh To Tuan, Lan Anh Le Thi, Nam Nguyen Thanh, Soamarat Vilaiyuk; Data Collection or Processing: Ha Nguyen Thi, Cuong Pham Manh, Lan Anh Le Thi, Nam Nguyen Thanh; Analysis or Interpretation: Ha Nguyen Thi, Cuong Pham Manh, Linh To Tuan, Lan Anh Le Thi, Nam Nguyen Thanh, Soamarat Vilaiyuk; Literature Search: Ha Nguyen Thi, Cuong Pham Manh; Writing: Ha Nguyen Thi, Cuong Pham Manh, Linh To Tuan, Lan Anh Le Thi, Nam Nguyen Thanh, Soamarat Vilaiyuk.

\section{REFERENCES}

1 McCANCE RA. Osteomalacia with Looser's nodes (Milkman's syndrome) due to a raised resistance to vitamin D acquired about the age of 15 years. $Q J$ Med 1947 ; 16: $33-46$.

2 Prader A, Illig R, Uehlinger E, Stalder G. [Rickets following bone tumor]. Helv Paediatr Acta 1959; 14: 554-565.

3 Drezner MK. [Tumor induced osteomalacia]. Rev Endocr Metab Disord 2001; 2: 175-186.

4 Burckhardt M-A, Schifferli A, Krieg AH, Baumner D, Szinnai G, Rudin C. Tumor-associated FGF-23-induced hypophosphatemic rickets in children: a case report and review of the literature. Pediatr Nephrol 2015; 30: 179-182.

5 Chong WH, Molinolo AA, Chen CC, Collins MT. Tumor-induced osteomalacia. Endocr Relat Cancer 2011; 18: R53-77.

6 Florenzano P, Gafni RI, Collins MT. Tumor-induced osteomalacia. Bone Rep 2017; 7: 90-97. 
7 Jiang Y, Xia W, Xing X, Silva BC, Li M, Wang O et al. Tumor-induced osteomalacia: An important cause of adult-onset hypophosphatemic osteomalacia in China: Report of 39 cases and review of the literature. J Bone Miner Res 2012; 27: 1967-1975.

8 Shah R, Lila AR, Jadhav R-S, Patil V, Mahajan A, Sonawane S et al. Tumor induced osteomalacia in head and neck region: single center experience and systematic review. Endocr Connect 2019; 8: 1330-1353.

9 Jih MK, Kim JS. Three types of ossifying fibroma: A report of 4 cases with an analysis of CBCT features. Imaging Sci Dent 2020; 50:65-71.

10 Sandoval MAS, Palermo MA, Carrillo R, Bundoc R, Carnate JM, Galsim RJ. Successful treatment of tumour-induced osteomalacia after resection of an oral peripheral ossifying fibroma. BMJ Case Rep 2017; : bcr2016218637.

11 Ryhänen EM, Schalin-Jäntti C, Matikainen N. Prolonged Hypophosphatemia and Intensive Care After Curative Surgery of Tumor Induced Osteomalacia: A Case Report. Front Endocrinol 2021; 12: 686135 .

12 Crossen SS, Zambrano E, Newman B, Bernstein JA, Messner AH, Bachrach LK et al. Tumor-induced Osteomalacia in a $3-1$ Pediatr Hematol Oncol 2017; 39: e21-e24.

13 Fernandez-Cooke E, Cruz-Rojo J, Gallego C, Romance AI, Mosqueda-Pena R, Almaden Y et al. Tumor-Induced Rickets in a Child With a Central Giant Cell Granuloma: A Case Report. PEDIATRICS 2015; 135: e1518-e1523.

14 Reyes-Múgica M, Arnsmeier SL, Backeljauw PF, Persing J, Ellis B, Carpenter TO. Phosphaturic Mesenchymal Tumor-Induced Rickets. Pediatr Dev Pathol 2000; 3: 61-69.

$15 \mathrm{Wu} \mathrm{H}$, Bui MM, Zhou L, Li D, Zhang H, Zhong D. Phosphaturic mesenchymal tumor with an admixture of epithelial and mesenchymal elements in the jaws: clinicopathological and

immunohistochemical analysis of 22 cases with literature review. Mod Pathol 2019; 32: 189-204.

16 Emodi O, Rachmiel A, Tiosano D, Nagler RM. Maxillary tumour-induced osteomalacia. Int J Oral Maxillofac Surg 2018; 47: $1295-1298$.

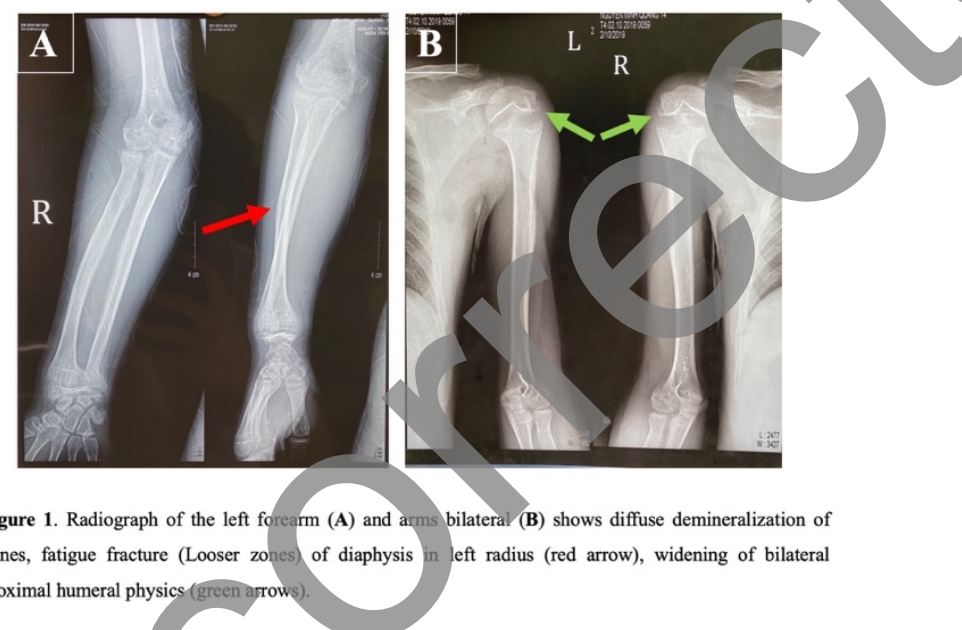



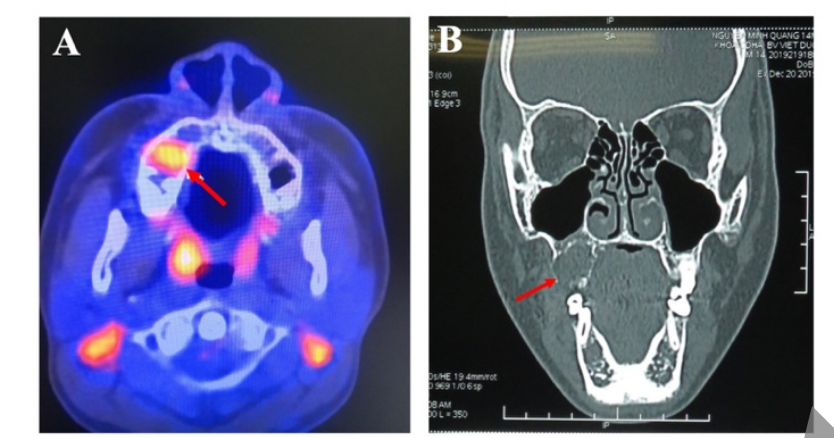

(

Figure 2. (A) $)^{18} \mathrm{FDG}-\mathrm{PET} / \mathrm{CT}$, (B) CT scanner, TIW images show a osteolytic lesion in the right max

$0^{\circ}$

(O) 
Table 1. Review of clinical, laboratory, and outcome of head and neck pediatric TIO cases

\begin{tabular}{|c|c|c|c|c|c|c|c|c|c|c|c|}
\hline $\begin{array}{c}\text { Case } \\
\text { no. }\end{array}$ & References & $\begin{array}{r}\text { Age/Sex } \\
\text { (years) }\end{array}$ & $\begin{array}{c}\text { Duration of } \\
\text { osteomalacia } \\
\text { (months) }\end{array}$ & $\begin{array}{c}\text { Symptoms } \\
\text { at } \\
\text { Location }\end{array}$ & $\begin{array}{c}\text { Serum } \\
\text { Phosphate } \\
(\mathrm{mmol} / \mathrm{L})\end{array}$ & $\begin{array}{l}\text { Serum } \\
\text { FGF23 } \\
(\mathrm{pg} / \mathrm{mL})\end{array}$ & $\begin{array}{l}\text { Localization } \\
\text { Methods }\end{array}$ & $\begin{array}{l}\text { Tumor } \\
\text { Region }\end{array}$ & $\begin{array}{l}\text { istopatholo } \\
\text { Results }\end{array}$ & Treatment & Outcome \\
\hline 1 & Reyes (14) & $9 \mathrm{~F}$ & 1.5 & Normal & 0.52 & NA & & & -MCT & Surgery & Recover \\
\hline 2 & $\mathrm{Wu}(15)$ & $15 \mathrm{~F}$ & 24 & NA & NA & NA & & & PMT & Surgery & Recover \\
\hline 3 & $\begin{array}{l}\text { Fernandez- } \\
\text { Cooke(13) }\end{array}$ & $3 \mathrm{M}$ & 6 & $\begin{array}{l}\text { Visible } \\
\text { tumor }\end{array}$ & 0.84 & & & rilla & CGCG & $\begin{array}{c}\text { Surgery, } \\
\text { Local Steroid } \\
\text { Infiltration }\end{array}$ & Recover \\
\hline 4 & $\begin{array}{l}\text { O.Emodi } \\
(16)\end{array}$ & $18 \mathrm{~F}$ & 72 & $\begin{array}{l}\text { Soft } \\
\text { tissue }\end{array}$ & 0.42 & & & $\begin{array}{c}\text { Left } \\
\text { Maxilla }\end{array}$ & $\begin{array}{c}\text { Fibro-osseous } \\
\text { lesions }\end{array}$ & Surgery & Recover \\
\hline 5 & $\begin{array}{c}\text { Crossen } \\
\text { (12) }\end{array}$ & $3 \mathrm{M}$ & 6 & $\begin{array}{l}\text { Ulcerated } \\
\text { lesions. }\end{array}$ & & 450 & PE & $\begin{array}{l}\text { Maxilla } \\
\text { and } \\
\text { Mandible }\end{array}$ & CGCG & $\begin{array}{c}\text { Surgery, } \\
\text { Local } \\
\text { Triamcinolone } \\
\text { Injection }\end{array}$ & Recover \\
\hline & $\begin{array}{c}\text { Present } \\
\text { Case }\end{array}$ & $14 \mathrm{M}$ & 10 & & 0.32 & 159.3 & ${ }^{18}$ FDG-PET & $\begin{array}{c}\text { Right } \\
\text { Maxilla }\end{array}$ & OF & Surgery & Recover \\
\hline
\end{tabular}

F, female; M, male; MRI, magnetic resonance imaging; NA, not available; OF, ossifying fibroma; PE, physical examination; PMTMCT, phosphaturic mesenchymal tumor mixed connective tissue type; PMT, phosphaturic mesenchymal tumor; CGCG, central giant cell granuloma . 
